\title{
Review
}

\section{Memantine for the Treatment of Dementia: A Review on its Current and Future Applications}

\author{
Jaume Folch $^{\mathrm{b}, \mathrm{c}}$, Oriol Busquets ${ }^{\mathrm{a}, \mathrm{b}, \mathrm{c}, \mathrm{e}}$, Miren Ettcheto ${ }^{\mathrm{a}, \mathrm{b}, \mathrm{c}, \mathrm{e}}$, Elena Sánchez-López ${ }^{\mathrm{c}, \mathrm{f}, \mathrm{g}}$, \\ Ruben Dario Castro-Torres ${ }^{\mathrm{a}, \mathrm{c}, \mathrm{d}, \mathrm{e}, \mathrm{j}}$, Ester Verdaguer ${ }^{\mathrm{a}, \mathrm{c}, \mathrm{d}, \mathrm{e}}$, Maria Luisa Garcia ${ }^{\mathrm{f}, \mathrm{g}}$, Jordi Olloquequi ${ }^{\mathrm{h}}$, \\ Gemma Casadesús $^{\mathrm{i}}$, Carlos Beas-Zarate ${ }^{\mathrm{j}}$, Carme Pelegric ${ }^{\mathrm{c}, \mathrm{e}, \mathrm{k}}$, Jordi Vilaplana ${ }^{\mathrm{c}, \mathrm{e}, \mathrm{k}}$, \\ Carme Auladell ${ }^{\mathrm{c}, \mathrm{d}, \mathrm{e}}$ and Antoni Camins ${ }^{\mathrm{a}, \mathrm{c}, \mathrm{e}, *}$ \\ ${ }^{a}$ Departament de Farmacologia, Toxicologia i Química Terapèutica, Facultat de Farmàcia i Ciències \\ de l'Alimentació, Universitat de Barcelona, Barcelona, Spain \\ ${ }^{\mathrm{b}}$ Departament de Bioquímica, Facultat de Medicina i Ciències de la Salut, Universitat Rovira i Virgili, \\ Reus, Spain \\ ${ }^{\mathrm{c}}$ Biomedical Research Networking Centre in Neurodegenerative Diseases (CIBERNED), Madrid, Spain \\ ${ }^{\mathrm{d}}$ Departament de Biologia Cellular, Fisiologia i Immunologia, Facultat de Biologia, Universitat \\ de Barcelona, Barcelona, Spain \\ ${ }^{\mathrm{e}}$ Institut de Neurociències, Universitat de Barcelona, Barcelona, Spain \\ ${ }^{\mathrm{f}}$ Unitat de Farmàcia, Tecnologia Farmacèutica i Fisico-química, Facultat \\ de Farmàcia i Ciències de l'Alimentació, Universitat de Barcelona, Barcelona, Spain \\ ${ }^{\mathrm{g}}$ Institute of Nanoscience and Nanotechnology (IN2UB), University of Barcelona, Barcelona, Spain \\ ${ }^{\mathrm{h}}$ Instituto de Ciencias Biomédicas, Facultad de Ciencias de la Salud, Universidad Autónoma de Chile, \\ Talca, Chile

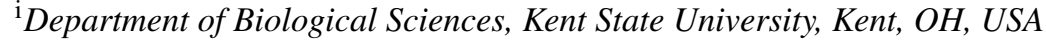 \\ ${ }^{j}$ Departamento de Biología Celular y Molecular, Laboratorio de Regeneración y Desarrollo Neural, \\ Instituto de Neurobiología, CUCBA, México \\ ${ }^{\mathrm{k}}$ Departament de Bioquímica i Fisiologia, Secció de Fisiologia, Facultat de Farmàcia i Ciències \\ de l'Alimentació, Universitat de Barcelona, Barcelona, Spain
}

Accepted 6 October 2017

\begin{abstract}
Alzheimer's disease (AD) is a neurodegenerative disorder characterized by the presence in the brain of extracellular amyloid- $\beta$ protein $(\mathrm{A} \beta)$ and intracellular neurofibrillary tangles composed of hyperphosphorylated tau protein. The N-MethylD-aspartate receptors (NMDAR), ionotropic glutamate receptor, are essential for processes like learning and memory. An excessive activation of NMDARs has been associated with neuronal loss. The discovery of extrasynaptic NMDARs provided a rational and physiological explanation between physiological and excitotoxic actions of glutamate. Memantine (MEM), an antagonist of extrasynaptic NMDAR, is currently used for the treatment of AD jointly with acetylcholinesterase inhibitors. It has been demonstrated that MEM preferentially prevents the excessive continuous extrasynaptic NMDAR disease activation and therefore prevents neuronal cell death induced by excitotoxicity without disrupting physiological synaptic activity. The problem is that MEM has shown no clear positive effects in clinical applications while, in preclinical stages, had very promising
\end{abstract}

\footnotetext{
${ }^{*}$ Correspondence to: Antoni Camins, PhD, Unitat de Farmacologia i Farmacognòsia, Facultat de Farmàcia i Ciències de l'Alimentaciò, Universitat de Barcelona, Barcelona, Spain. Av.
} 
results. The data in preclinical studies suggests that MEM has a positive impact on improving AD brain neuropathology, as well as in preventing $A \beta$ production, aggregation, or downstream neurotoxic consequences, in part through the blockade of extrasynaptic NMDAR. Thus, the focus of this review is primarily to discuss the efficacy of MEM in preclinical models of $\mathrm{AD}$, consider possible combinations of this drug with others, and then evaluate possible reasons for its lack of efficacy in clinical trials. Finally, applications in other pathologies are also considered.

Keywords: Alzheimer's disease, amyloid $\beta$-protein, extrasynaptic N-Methyl-D-aspartate receptor, memantine, tau protein

\section{INTRODUCTION}

Alzheimer's disease (AD) is a neurodegenerative pathology of severe prognosis, currently incurable, and highly prevalent in aged people [1]. The first description of the disease was carried out in 1906 by a German psychiatrist and neurologist, Alois Alzheimer, when exploring the brain tissue of a patient, Auguste Deter, who had died from a mental illness unknown at that time [2,3]. Today, it is the cause of 50-70\% of dementia cases and, according to the Alzheimer's Association, 13\% of people over 65 in developed countries suffer from $\mathrm{AD}$, where it is the fifth cause of death in patients of this age group $[1,4]$. If unchecked, global incidence will quadruple to 114 million by 2050 according to population growth projections by the World Health Organization (WHO) [1]. This would imply unsustainable economic burdens for all health systems, in addition to its social impact.

AD can be classified according to the age at which it begins to manifest, that is, if it has an early onset, developing before the age of 65 (3-5\% prevalence), or if it occurs after the 65 years of age (95-97\% prevalence) [1]. Additionally, the pathology may be of hereditary or sporadic origin, the latter being the most common (98\% prevalence). Pathogenesis of late onset $\mathrm{AD}$ is very complex. Other than aging, which is the main factor involved in the development of the disease, it may be associated with dietary and environmental factors, including long term consumption of high caloric diets and sedentary lifestyles $[1,4]$. Overall, it is the interaction of multiple genetic and environmental risk factors that lead to $\mathrm{AD}$, together with the disruption of epigenetic mechanisms controlling gene dynamics and expression [4-10].

The main symptom of AD is memory loss, which is correlated with a decline of neuron population in the hippocampus, a brain area critical for learning and memory $[9,10]$. In addition, the entorhinal cortex, area of interface between the hippocampus and the neocortex for the formation of spatial memory, becomes affected by this pathology. It has been reported that the hippocampus is especially vulnerable to damage at early stages in $\mathrm{AD}$ and approximately $25-70 \%$ of neurons are lost in this area $[9,10]$.

In the familial form of the disease, $A \beta$ peptide formation, in particular its longer form $A \beta_{42}$, is triggered by mutations in the amyloid- $\beta$ protein precursor (A $\beta P P$, chromosome 21), presenilin 1 (PS1, chromosome 14), and presenilin 2 (PS2, chromosome 1) genes. Also, the APOE gene, another risk factor for the development of $\mathrm{AD}$, has been characterized $(\varepsilon 2$, $\varepsilon 3$, and $\varepsilon 4)[1,4,10-12]$. It has been described that the $\varepsilon 2$ allele has a protective role in $\mathrm{AD}$, while $\varepsilon 4$ has the opposite effect, since it favors the appearance of $\mathrm{AD}$. Although late onset $\mathrm{AD}$ appears with higher incidence when the $\varepsilon 4$ isoform is affected, the exact mechanism of how APOE triggers the formation of amyloid deposits is unknown $[11,12]$. The lack of knowledge on the actual mechanisms that trigger the appearance of this multifactorial disease is the exact cause that leads us to having no cure for its treatment [11-13].

Memantine (MEM), a low-affinity voltagedependent uncompetitive antagonist of NMDA receptors (NMDAR), is currently being prescribed for the treatment of AD jointly with acetylcholinesterase inhibitors such as galantamine, donepezil, and rivastigmine [11, 14-17]. Since it is a low-affinity antagonist, it blocks the NMDAR but it is rapidly displaced from it, avoiding prolonged receptor blockade and the associated negative side effects on learning and memory that have been observed in high affinity NMDAR antagonists (dissociative anesthetics, ketamine, and MK-801). MEM also has a suitable safety and tolerability limits showing a good therapeutic margin. Another advantage of MEM is that it only interacts with the channel when it is pathologically activated under an excessive glutamate concentration in the synaptic cleft, as is the case with AD. In addition, preclinical data has reported that MEM could block other receptors, such as nicotinic, acetylcholine, serotonin, and sigma-1 receptors [17-19]. 
Historically, MEM was first synthesized by the Eli Lilly laboratories as a compound for the treatment of diabetes, but it was ineffective [14, 15, 20-24]. In 1972, Merz Pharma applied for a German patent presenting MEM as a potential treatment for various neurological diseases $[14,15]$. In the early 1990 s, the company initiated the research of efficacy and safety of MEM in nursing patients with severe dementia. In 1999, Forest Laboratories acquired the license for using MEM and initiated a series of clinical studies in both moderate to severe AD. MEM was approved for the treatment of moderately severe to severe $A D$ in 2002 by the European Agency for the Evaluation of Medical Products (EMEA). Complementarily, the efficacy of MEM was evaluated as monotherapy or combined with acetylcholinesterase inhibitors [24]. The dosing regimen of $10 \mathrm{mg}$ bid was based on previous clinical trial experience.

So far though, the biggest problem that is encountered with MEM and any other approved treatment for $\mathrm{AD}$, is that they do not slow down the progression of the disease, but only have symptomatic effect [26]. That is why current efforts in AD therapy are focusing on the research and development of new molecules that can modify the course of AD progression [27, 28]. Among the major drugs that are in development, we observe some already in Phase III: inhibitors of the $\beta$-site amyloid precursor protein cleaving enzyme (BACE) (CNP520, LY3314814, and verubecestat) and antibodies against the $A \beta$ peptide (aducanumab, solanezumab, crenezumab, gantenerumab, and BAN2401) [22, 27].

Because MEM has already been approved and used for $\mathrm{AD}$ and data points out possible combinations with other drugs in the future, in this review we will evaluate the different reported results on MEM at the preclinical levels on different stages of AD progression. Also, the different mechanisms involved in the beneficial effects of MEM in the preclinical levels will be discussed. Finally, the lack of MEM efficacy on clinical AD and the potential use of MEM in neurological diseases will be discussed.

\section{SYNAPTIC AND EXTRASYNAPTIC METHYL-D-ASPARTATE RECEPTORS (NMDAR)}

The NMDAR are cationic channels controlled by the excitatory neurotransmitter glutamate, which plays an essential role in the physiological process of learning and memory in the central nervous system (CNS) [14, 15, 20-26]. The NMDAR can be classified in different subunits called NR1 and NR2A-D [14, 15, 21-25]. In AD, an excessive release of glutamate and, an increasing concentration of soluble $A \beta$, which has been hypothesized to increase the activity of the receptor [23] and lead to an excessive $\mathrm{Ca}^{2+}$ flux within the cell, as well as free radical generation. The intense influx of $\mathrm{Ca}^{2+}$ impairs mitochondrial function activating transition pores in the inner mitochondrial membrane, which causes the release of cytochrome $\mathrm{c}$, the posterior depletion of ATP, and simultaneous formation of reactive oxygen species (ROS) [23]. These cytotoxic events are associated with synaptic dysfunction and tau phosphorylation. [23].

Depending on the localization of the NMDAR in the neuron, they have been classified in two groups $[20,22]$ :

- The synaptic NMDARs have both presynaptic and postsynaptic locations on neurons [29]. The presynaptic receptors play a role in synaptic transmission and plasticity of neuronal networks, while postsynaptic only have a role in the control of plasticity [28-31]. Both types are involved in the activation of neuronal protective and survival genes [29, 30].

- Extrasynaptic NMDARs are located on dendrites and require high glutamate concentrations in order to be activated [31]. These NMDARs are characterized by favoring the NR2B subunit which, when excessively stimulated, contribute to neurotoxicity and the control of neuronal cell death. Moreover, extrasynaptic NMDARs are involved in the regulation of $A \beta$ production and thus in the neuropathology of AD [29-32]. They are the main target of MEM.

According to this information, MEM is the only approved antagonist against extrasynaptic NMDARs and the treatment of AD. Its selective action without affecting the physiological NMDAR synaptic activity allows neuroprotective effects brain [20-23].

\section{CLINICAL PATHOPHYSIOLOGY OF ALZHEIMER'S DISEASE}

Initial postmortem brain histopathological examination of $\mathrm{AD}$ patients led to the characterization of the two classical hallmarks of the disease: senile plaques and neurofibrillary tangles (NFT) $[1,4,6,10$, $21,26,32]$. Senile plaques are extracellular deposits, 
diffuse or compact, that can be found in the brain of patients with $\mathrm{AD}$, and that are composed of insoluble $A \beta$ peptides of 39 to 43 amino acids [21]. Diffuse plaques are $A \beta$ deposits that do not visibly alter the surrounding neuropil, or induce glial response around them, and are considered relatively benign, since they have been found in cerebral cortex samples of elderly subjects that presented no cognitive impairment $[4,10]$. In contrast, compact plaques are often surrounded by dystrophic neurites, reactive astrocytes, and activated microglia, rendering them more neurotoxic. In addition, senile plaques may also contain mucopolysaccharides, $\alpha 1$-antiquimiotripsin, immunoglobulins, complement factors, fibrinogen, APOE, cholesterol, presenilins, cytokines (IL-1 $\beta$, IL-6, TGF- $\beta$, TNF- $\alpha$ ), intercellular adhesion molecule 1 (ICAM-1), clusterine, $\alpha$-synuclein, and inorganic elements [10].

The original hypothesis on the origin of $\mathrm{AD}$ was focused on alterations on the usual activity of the amyloid cascade [33-35]. This hypothesis is based on the following process: first, A $\beta P P$ is processed by the amyloidogenic route, a pathway in which $\beta$ - and $\gamma$-secretases cleave A $\beta P P$, causing an excessive production of $A \beta$ peptide and/or a defect of its elimination [33-39]. This process causes its oligomerization and accumulation in the form of senile plaques in the brain cortex, hippocampus, and other brain areas. To better understand the mechanism, it will be explained further:

Initially, the $A \beta$ peptide is generated from the catabolism of A $\beta P P$, a plasma membrane protein with a single domain found in different cell types, including neurons, astrocytes, oligodendrocytes, and glial cells. It is encoded by a gene located on chromosome 21, which when expressed gives rise to 8 isoforms, of which APP695 is the most abundant in the brain [38]. This protein is cleaved by $\alpha$-, $\beta$, and $\gamma$-secretase enzymes and a complex of proteins containing PS1. In a physiological situation, following the non-amyloidogenic pathway, A $\beta P P$ is catabolized by $\alpha$-secretases, producing a $\operatorname{sA} \beta P P \alpha$ fragment that remains in the extracellular space, and a carboxyl-terminal fragment of 83 amino acids (C83), that is anchored on the plasma membrane [35-39]. $\mathrm{sA} \beta \mathrm{PP} \alpha$ regulates neuronal excitability, improves synaptic plasticity, learning, and memory, and also increases the resistance of neurons to oxidative and metabolic stress. However, in neuropathological situations, A $\beta P P$ is metabolized by the amyloidogenic pathway in which the $\beta$ amyloid cleaving enzyme 1 (BACE $1 ; \beta$-secretase) breaks A $\beta$ PP by the
$\mathrm{N}$-terminal end while $\gamma$-secretases cleave the C-terminal end, obtaining fragments $A \beta_{40}$ and $A \beta_{42}$ that remain in the extracellular space and cause negative effects.

In addition, it is believed that in non-pathological conditions the $\mathrm{A} \beta$ peptide is produced continuously and that its aggregation and deposition in $\mathrm{AD}$ is the consequence of its rise on concentration that makes it precipitate $[38,39]$. In physiological conditions, the amyloid protein is produced in normal amounts in its soluble form due to cleavage of $A \beta P P$ by the $\alpha$-secretase enzyme, and is eliminated by the action of degrading enzymes such as neprilysin, the insulin-degrading enzyme, and the angiotensin converting enzyme I. Yet, when sporadic AD occurs, the balance between the non-amyloidogenic and the amyloidogenic pathway becomes altered and, there is an excessive production of $A \beta$, resulting from the cleavage of $A \beta P P$ by the $\beta$ - and $\gamma$-secretase enzymes and a lower degradation of $A \beta$ due to a lower activity of the degrading enzymes previously mentioned, thus causing an imbalance between the production and elimination of $A \beta$ [33-40].

However, even though there is a demonstrated role of senile plaques on this excitotoxicity that leads to $\mathrm{AD}$, these events do not always correlate, and soluble $A \beta$ might the one responsible for synaptic loss and the symptomatology of $\mathrm{AD}$ [35-40]. In addition, over the years it has been demonstrated that high $A \beta$ levels in the brain lead to NFT formation, cell loss, vascular damage, and dementia $[10,40]$. The presence of NFTs, which are intracellular deposits of helical paired filaments composed of abnormally hyperphosphorylated tau protein, is well characterized in AD brains [36-40]. The physiological function of tau is related to the stabilization of the microtubule polymerization and proper axon functionality and, to a lesser extent, the structuration of dendrites and dendritic spines in neurons when interacting with tubulin $[41,42]$. Tau regulates axonal transport of proteins, vesicles, and organelles. In $\mathrm{AD}$, tau hyperphosphorylation causes abnormal associations with tubulin, favoring cytoskeleton alterations [42]. This aberrant association causes for the filaments of tau to become insoluble and precipitate as NFTs in synapses, axonal structures, and neuronal bodies, causing neuronal death by apoptosis [40-42].

In the end, all these cascade mechanisms, along with the previously described alterations issued by the NMDAR interacting with the $A \beta$, add up to the appearance of dementia due to neuronal activity decline without clear evidence on the real culprit. 


\section{EFFECTS OF MEMANTINE ON THE AMYLOID CASCADE}

Due to the negative consequences derived of the presence of compact senile plaques in the brain, they have become one of the main targets when trying to design appropriate treatments for AD. Several preclinical studies have reported that MEM leads to a reduction in $A \beta$ brain levels or reduces amyloid plaque burden in preclinical mice models of $\mathrm{AD}$, which contributes to memory improvement [43]. Specifically, 3-month-old APP/PS1 mice treated with MEM $(10 \mathrm{mg} / \mathrm{kg} /$ day; i.p.) for a period of 4 months showed a significant decrease in amyloid plaque burden in the brain (cortex and hippocampus) [44]. Furthermore, MEM was effective improving shortterm memory deficits in APP/PS1 mice, based in exploratory behavior results using the novel-object recognition test [44]. Moreover, Liu and colleagues treated 12-month-old APP/PS1 mice with MEM ( $5 \mathrm{mg} / \mathrm{kg}$ body weight) via intragastric administration and, they demonstrated that MEM treatment improved memory and learning impairment and significantly decreased $\mathrm{A} \beta$ deposits in mice brains [45]. Parsons and colleagues demonstrated that after a chronic in vitro treatment, MEM was accumulated in the phospholipid membrane and could have modulatory effects on membrane fluidity [46]. This effect could also modulate activity of membrane-bound enzymes, such as A $\beta P P$ and BACE- 1 and probably explain the anti-A $\beta$ effects of MEM.

Recently, Ito and colleagues reported that MEM reduces the brain levels of $A \beta$ in $\operatorname{Tg} 2576$ mice that have plaques and the levels of insoluble endogenous $A \beta$ in aged F344 rat brains. Authors suggest a new mechanism involved through the modulation of $A \beta P P$ trafficking and stabilization of $A \beta P P$ on the cell surface, which favors a reduction in $A \beta$ production [47].

Therefore, after evaluating the results, some authors have suggested that MEM effects on NMDAR do not only associate the neuroprotective effect observed with its administration. Some authors reported that there are additional mechanisms in MEM neuroprotection like nerve growth factor upregulation that activates the tropomyosin receptor kinase A (Trk A) signaling, which eventually inhibits p75 neurotrophin receptor (p75NTR), molecules implicated in neuronal plasticity [48]. In addition, it causes increases on brain levels of the brain-derived neurotrophic factor (BDNF) and Trk B and muscarinic receptors [48]. Furthermore, MEM attenuated $A \beta_{42}$-induced loss of cholinergic neurons and microglia activation in the neocortex [49]. Interestingly, no beneficial effects were observed after subchronic MEM treatments in 5XFAD mice at $12-15$ months of age [50]. Authors suggest that MEM cannot protect from memory loss at advanced disease stages due to high levels of $A \beta$ in the tissue.

Thus, although in preclinical models it has been demonstrated that MEM memory improvement is due to reduction of cerebral $A \beta$ levels and amyloid burden, in this study it was suggested that MEM improves hippocampal memory in young 5XFAD mice by blocking extrasynaptic NMDARs without affecting $A \beta$ levels. In addition, authors suggest that a suitable $\mathrm{AD}$ treatment might be the co-administration of an $A \beta$-lowering therapy ( $\beta$-secretase inhibitors to reduce $A \beta$ production) together with MEM (which prevents synaptic toxicity of oligomeric $A \beta$ ). These

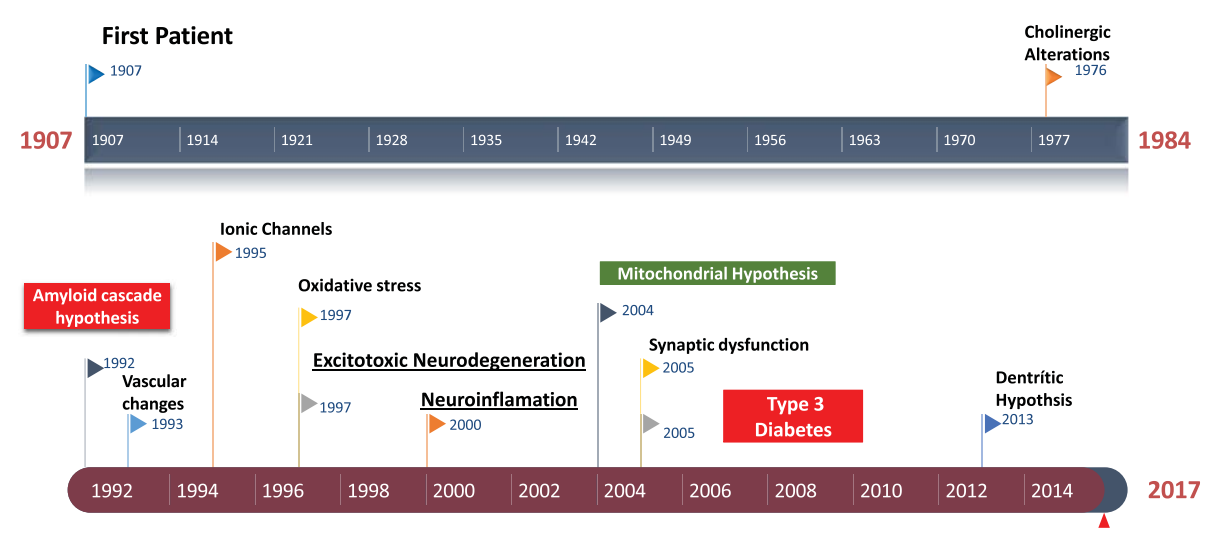

Fig. 1. Historical perspective of Alzheimer's disease. Amyloid cascade hypothesis was suggested in 1992. The role of excitotoxicity in AD was suggested about 1997. 


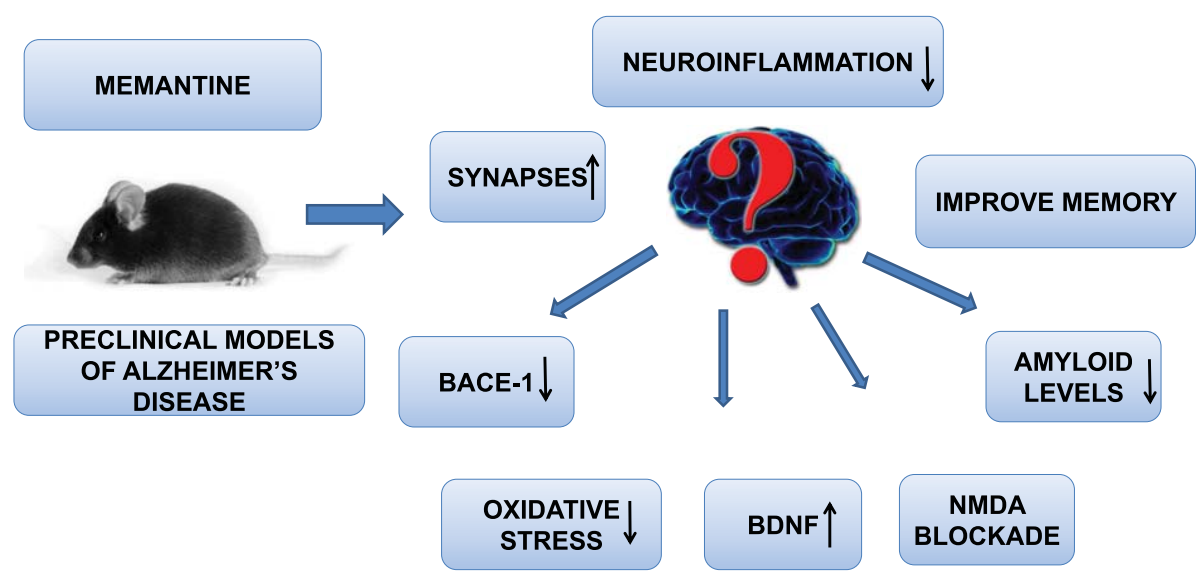

Fig. 2. Memantine improve preclinical Alzheimer's disease neuropathology though increasing BDNF levels, synapses, improving cognition, decreasing neuroinflammation, BACE-1 blockade, and NMDA receptor inhibition.

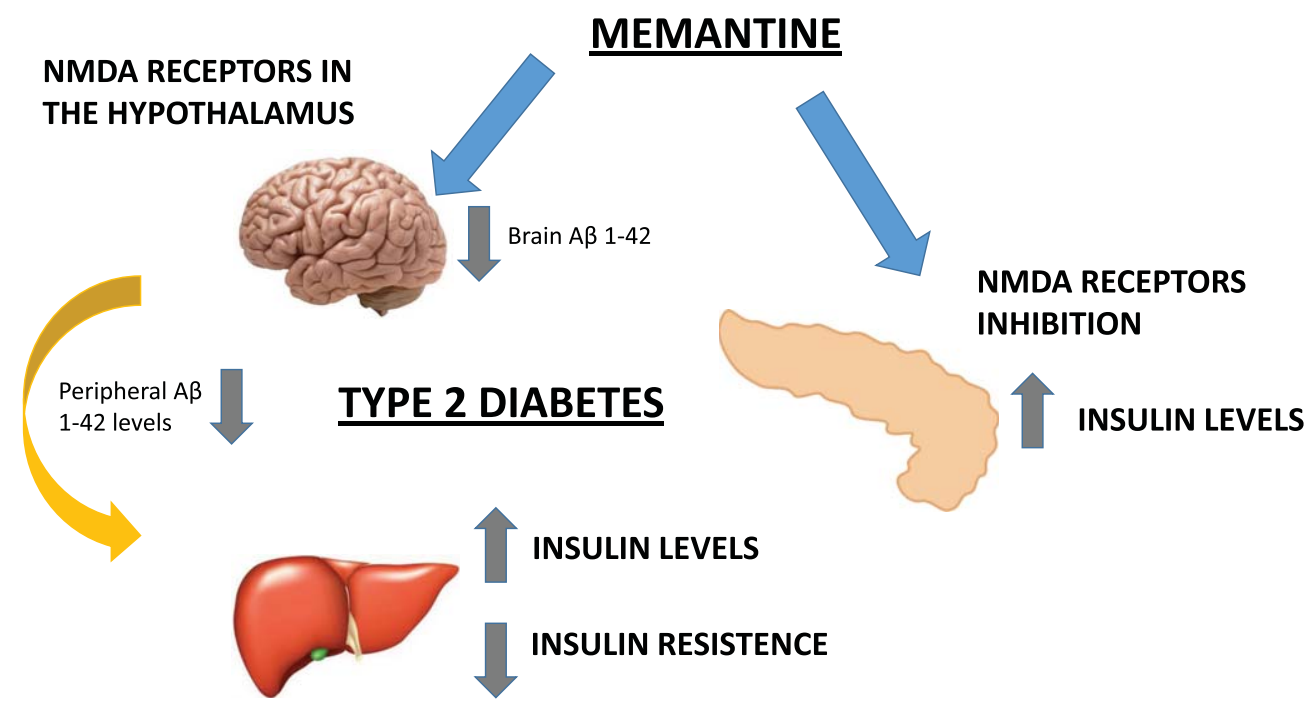

Fig. 3. We hypothesized that the potential beneficial metabolic effects of MEM are mediated by the inhibition of peripheral (pancreatic) NMDAR and the blockade of hypothalamic $A \beta_{1-42}$ levels. Therefore, AD could be a cognitive disorder associated to metabolic alterations both in central (insulin receptors) and peripheral areas.

data in experimental models of AD with old 5XFAD mice could probably explain why the clinical efficacy of the monotherapeutic MEM approach is lost in moderate to severe memory deficits in advanced AD patients [37]. Likewise, De Felice group reported the importance of $A \beta$ oligomer species in the mechanisms of pathogenesis of $\mathrm{AD}$ [51]. A $\beta$ oligomers self-assemble to form multiple types of soluble oligomers (AßOs) including low molecular weight (dimers, trimers, tetramers) and high molecularweight species ranging in mass from 54 to $150 \mathrm{KDa}$. $\mathrm{A} \beta \mathrm{O}$ s are involved in the process of synaptic and cognitive dysfunction in AD. In this study, authors demonstrate that MEM was effective only on high molecular-weight oligomers and concluded that the limited clinical efficacy of MEM in AD could be explained by this selectivity [51].

\section{MEMANTINE INHIBITS NEUROFIBRILLARY TANGLES FORMATION AT PRECLINICAL LEVEL}

It is well known that the process of tau hyperphosphorylation at multiple sites is controlled by several serine/threonine kinases, including protein kinase A, c-Jun N-terminal Kinase (JNK), Fyn kinase, 5' adenosine monophosphate-activated 
protein kinase, glycogen synthase kinase $3 \beta$ (GSK3 $\beta$ ), cyclin dependent kinase 5 (CDK5), microtubule affinity regulating kinase, extracellular signal regulated kinase 2 , and $\mathrm{Ca} 2+/$ calmodulin-dependent protein kinase II [52-57]. Thus, these kinases increase the phosphorylation of tau and prevent the ability of tau to promote microtubule assembly and facilitate the polymerization of tau into paired helical filament. The process of tau dephosphorylation in the brain is mainly regulated by the protein phosphatase 2A.

Kamat and colleagues suggest that NMDAR activation increases tau phosphorylation by a combined process with oxidative stress. It activates the CDK5 signaling pathway and stress-activated protein kinases JNK/SAPK [58]. So, considering the elements we have already reviewed, the interaction of the $A \beta$ peptide with the NMDAR favors an increase on the concentration of intracellular $\mathrm{Ca}^{2+}$, which activates the CDK5 and SAPK/JNK that, in the end, induce the hyperphosphorylation of tau protein.

Briefly, the mechanisms through which kinases named above phosphorylate tau are described below.

\section{CDK5-mediated tau phosphorylation}

CDK5 belongs to the family of cyclin-dependent Ser/Thr protein kinases (CDKs) and carries out the activation and maintenance of numerous physiological functions in the nervous system, including neurite and axon growth [43]. The accumulation of $A \beta$, as well as oxidative stress and other mechanisms of excitotoxicity, can lead to canonical activation of calpain through significant increases of $\mathrm{Ca}^{2+}$ in the cytoplasm after NMDAR activation [59]. When active, calpain binds to CDK5 and favors its overactivation and phosphorylation of proteins such as tau. Zimmer and colleagues demonstrated that MEM prevented hippocampal activation of CDK5 after brain okadaic acid administration, which induces AD-like phenotype in rats [60].

\section{GSK3 $\beta$-mediated phosphorylation}

Increasingly, AD is being linked to insulin resistance [61]. Insulin molecules bind to their receptors and activates them. The phosphoinositol 3 kinase binds to this receptor by the $\mathrm{SH} 2$ domain and converts the phosphatidylinositol-4,5-bisphosphate into phosphatidylinositol-3,4,5-triphosphate, which binds to the protein kinase B (AKT), a Ser/Thr kinase. AKT is then phosphorylated and activated by phosphoinositide-dependent kinase, which in turn phosphorylates GSK3 $\beta$ [62]. The Ser/Thr protein kinase GSK-3 $\beta$ contains two distinct forms: an active form (Ser9 phosphorylated), which is the most abundant in the nucleus, mitochondria, and lipid membrane, and a cytosolic inactive form. AKT inactivates GSK-3 $\beta$ by phosphorylating it, activating anti-apoptotic mechanisms and antioxidant defenses [63-65]. When AD causes insulin resistance, the insulin receptor is not activated, so GSK3 $\beta$ would be on its active form and could phosphorylate the tau and cause neuronal death [61]. De Sarno and colleagues, as well as Martinez-Coria and colleagues, reported that MEM was able to inhibit GSK3 $\beta$ activation in different experimental models [66, 67]. Therefore, the modulation of GSK3 $\beta$ phosphorylation by MEM may contributes to the therapeutic actions of this drug used in the treatment of AD. These results were more significant since MEM improved additional AD hallmarks such as cognitive dysfunction, probably also associated in part, with inhibition of tau hyperphosphorylation, which governs the major synaptic dysfunction by forming tangles.

\section{RESULTS OF ALZHEIMER'S DISEASE APOE E4 CARRIER PATIENTS TREATED WITH MEMANTINE}

Although APOE $\varepsilon 4$ is a well characterized AD risk factor, the role of APOE $\varepsilon 4$ as a modulator of disease progression, and its pharmacogenetic effects on $\mathrm{AD}$ therapies, are a matter of controversy [67].

One the one hand, for example, Han and colleagues compared the efficacy of rivastigmine patch monotherapy or MEM plus rivastigmine patch in patients with mild to moderately severe $\mathrm{AD}$, presenting different polymorphisms of the APOE genotype [68]. The study demonstrated that the association MEM plus the rivastigmine transdermal patch therapy had beneficial effects on the activities of daily living (ADL) in moderately severe $\mathrm{AD}$ patients with the APOE $\varepsilon 4$ allele [68, 69]. On the other hand, Wroolie and colleagues evaluated the effects of MEM on cognition in women with risk of AD and included a control group for the genetic risk factor for $\mathrm{AD}$ the APOE $\varepsilon 4$ in a prospective open-label 6-month long pilot medication trial [70]. The results of this study were negative and authors concluded that this study does not support the potential usefulness of MEM in the prevention of cognitive decline or dementia [70]. 


\section{CONTROL OF THE DEVELOPMENT OF INFLAMMATORY RESPONSES AND OXIDATIVE STRESS BY MEMANTINE}

In $\mathrm{AD}$, it has been demonstrated that neuroinflammatory responses derived of glial activation play a prominent role in the induction of oxidative stress [71]. Thus, several studies have reported a decreased risk of AD in patients taking non-steroidal anti-inflammatory drugs (NSAID) [72]. Furthermore, long-term use of NSAIDs appears to be effective in reducing the incidence of $\mathrm{AD}$ [72]. In addition, the vast majority of studies of MEM focus mainly on its effects on neurons, while MEM interacts with other cell types in the CNS $[14,15,73]$. In preclinical models of this disease, neuroinflammatory markers like microglia and astroglia reactivity have been observed, yielding interesting results and showing decreases in neuroinflammatory biomarkers after MEM treatments.

Usually, in the brains of AD patients, microglial cells are highly reactive, mobile, and located close to amyloidal plaques. It has been hypothesized that this cell type could have different roles in the complex mechanisms that lead to the appearance of neuropathological conditions [71]. Firstly, microglia would have a protective role in the initial stages of the disease, phagocyting A $\beta$ peptides. Secondly, when the disease progresses, microglia would be one of the responsible cell types in the development of proinflammatory and neurotoxic responses due to the release of molecules like cytokines [73]. The increase of substances such as TNF $\alpha$ and IL- $1 \beta$, jointly with mediators such as nitric oxide or ROS, produced by glial cells, favor an exacerbation of AD pathology $[71,73,74]$. In addition, IL- $1 \beta$ appears to induce $\mathrm{A} \beta \mathrm{PP}$ production, increasing $\mathrm{A} \beta$ brain levels, which in turn would induce further interleukin production by microglia. Thus, a positive feedback cycle would be created. Therefore, although clinical trials do not support the efficacy of NSAIDs, this group of drugs or others with similar properties may have a therapeutic effect on AD [71]. Interestingly, it has been reported that MEM has an anti-inflammatory action on microglial cells through the inhibition of inwardly rectifying $K^{+}$(Kir) channels [75].

An excellent study performed by Kaindl and colleagues reported the existence of microglial NMDAR that when overactivated, would cause the development of inflammatory responses and trigger brain damage processes [76]. They suggest a key role of microglial NMDARs in the secretion of neurotoxic factors such as interleukins, $\mathrm{TNF} \alpha$, ROS, and nitric oxide. In addition, these authors hypothesize that in the brain a neuron-glia positive feedback cycle is generated through glutamate release by neurons favoring glial activation [76]. Thus, MEM, through the blockade of glial NMDAR, could exert neuroprotective effects through anti-inflammatory mechanisms. This point was further demonstrated by De Felice and colleagues who reported that neuronal hippocampal cultures treated with $A \beta$ oligomers favor an increase in ROS formation through NMDAR activation [77]. They demonstrated the neuroprotective effects of MEM showing results of protection against synapsis loss.

$\mathrm{Wu}$ and colleagues reported that MEM increases the release of glial cell-derived neurotrophic factor (GDNF) from astroglia, which may account for its neuron survival-enhancing effect in primary neuron-glia cultures [78]. Caumont and colleagues also demonstrated on an in vitro study, that MEM administration in a C6 glioma cell line increased GDNF production, suggesting that MEM neuroprotective effects in brain neurons could be also due to the release of neurotrophic factors from glial cells [79]. Interestingly, neurotrophic effects of MEM were significantly inhibited when a neutralizing GDNF antibody was added to the cell cultures. Willard and colleagues reported that MEM also attenuated cytotoxic effects [80]. Specifically, MEM alleviated inflammatory processes mediated by chronical lipopolysaccharide administration into the basal forebrain of mice [81-83]. Consequently, it has been suggested that a chronical combined administration of MEM and NSAIDs could be a suitable strategy to delay the onset or slow the progression of $\mathrm{AD}$ [83].

\section{ALTERNATIVE APPLICATIONS OF MEMANTINE IN OTHER PATHOLOGIES RELATED TO THE MODULATION OF BRAIN BDNF LEVELS}

Meisner and colleagues were the first group to report new significant pharmacological actions of MEM unrelated with NMDAR blockade, the modification brain protein expression of BDNF [48]. In fact, they demonstrated that when administering MEM to rhesus monkeys (Macaca mulatta) infected with immunodeficiency virus (HIV), brain protein levels of BDNF increase. Likewise, studies with other NMDAR antagonists suggest that they can modulate the levels of brain BDNF, pointing to a 
potential role of glutamate in the activity of this neurotrophic factor [84]. Interestingly, several preclinical studies have evidenced that in addition to its applications for AD, MEM displays antidepressant-like effects in rodents subjected to experimental models of depression [85]. In addition, the co-administration in rodents with MEM and ketamine or MEM with sertraline, increased BDNF protein levels in the hippocampus of rats [86, 87]. In addition, using other NMDAR antagonists, the association of fluoxetine and amantadine also induced robust significant increases of both BDNF protein and mRNA gene expression in rodent brain [88]. An additional benefit of the use of MEM that is not related to neurodegenerative diseases, is its therapeutic application in the treatment of alcoholism. Specifically, it has been hypothesized that the results would be the consequence of the effects of MEM on BDNF and its role in alcohol consumption [89]. Finally, since BDNF is an inductor of the expression of markers for synaptogenesis, as well as, is a regenerator of on synaptic sites, Zhu and colleagues evaluated the effects of MEM in preclinical models of Parkinson's disease induced by the administration of 1-methyl-4-phenyl1.2.3.6-tetrahydropyridine [90]. This models causes for reductions of BDNF levels in the hippocampus, usually being associated with reductions to longterm potentiation. MEM treatment increased BDNF expression and restored long-term potentiation [90].

To summarize, all this data related to the effects of MEM on BDNF opens new possibilities on its possible applications for the treatment of neurological-neurodegenerative diseases [91].

\section{MEMANTINE TREATMENT HAS EFFECTS BOTH IN BRAIN AND PERIPHERAL METABOLIC BIOMARKERS RELATED TO DIABETES AND INSULIN METABOLISM}

Some studies have reported a close association between late onset $\mathrm{AD}$ and type 2 diabetes, a disorder usually related with obesity, going so far as demonstrating already severe impairments of glucose metabolism in mild cases of $\mathrm{AD}[8,13,92-97]$. Thus, lifestyle, particularly in terms of physical activity and diet, has important effects on health and cognitive processes, during aging in humans [13]. However, the interaction between obesity, aging, and $\mathrm{AD}$ is complex, with some evidence pointing out to the negative effects of obesity in early adulthood. Specifically, some authors have demonstrated that the development of obesity in those ages substantially increases the risk of developing AD [93-96]. This point is very interesting, since recent data suggests that $\mathrm{AD}$ should be considered as an affection of the entire organism and not only the brain, possibly having a partial origin in peripheral metabolic alterations [94, 95].

Following the same line of thought, Marquard and colleagues reported the presence of NMDARs in pancreatic $\beta$-cells [93]. These authors demonstrated that dextromethorphan (NMDARs antagonist) regulated insulin secretion in pancreas $[93,94]$. Dextromethorphan blocked NMDARs, preventing the activation of $K^{+}$channels, reducing its efflux from the cell, and prolonging the time the depolarized state of $\beta$-cells $[93,97]$. Consequently, intracellular $\mathrm{Ca}^{2+}$ concentration increased leading to insulin release and improvement of the diabetic state. However, even though the results are very interesting, it must be taken into account that strong NMDAR antagonists have considerable cognitive side effects and MEM, being a partial antagonist, might be a better choice for long-term drug usage [97-99].

Considering these results, the use of MEM could not only alleviate the symptomatology in the central nervous system but also in peripheral tissues. In our research group, we have studied the effects of MEM on APPswe/PS1dE9 mice fed with a highfat diet (unpublished results). The animals were fed with a high-fat diet until 7-8 months of age and they were treated with MEM-supplemented water $(30 \mathrm{mg} / \mathrm{kg})$ during the last 12 weeks. In this study, MEM improved peripheral metabolic parameters like insulin resistance. Moreover, MEM reduced the accumulation of $A \beta$ (mechanism already described in this review). This result is especially significant since Arrieta-Cruz reported that rat in vivo hypothalamic $A \beta_{25-35}$ administration altered peripheral regulation of glucose, showing that $\mathrm{A} \beta$ plays an important role in regulating glucose homeostasis [100, 101]. Correspondingly, it has been reported that deposits of $\mathrm{A} \beta$ peptides can be found in different non-neuronal tissues such as heart, liver, and pancreas as it was reported by Troncone and colleagues [102, 103]. Zhang and colleagues demonstrated in the APP/PS1 mice model of familial $\mathrm{AD}$, that $\mathrm{A} \beta$ induces insulin resistance in hepatocytes suggesting an important role of peripheral $A \beta$ in modulating systemic insulin sensitivity and glucose metabolism (A $\beta$ would bind directly to the insulin receptor, affecting its signaling [104, 105]. All these studies are of importance because they reinforce the evidence that late onset 
$\mathrm{AD}$ should be considered as a metabolic disorder denominated type 3 diabetes [8].

Finally, De Felice described that the neuroinflammatory process mediated mainly by the cytokine $\mathrm{TNF} \alpha$ could be another mechanism though which insulin signaling would be affected [5]. TNF $\alpha$ would bind to its receptor and induce a signaling cascade that would activate the JNK kinases among others [13]. The JNKs, specifically the JNK1 isoform, would be a direct inhibitor of the insulin receptor substrate 1, the substrate of the insulin receptor, being its activation cause for a reduction of insulin signaling and glucose up-take, an already described symptom of possible appearance of $\mathrm{AD}[5,13,96]$.

In the end, all the data adds up to the conclusion that there is a real interaction between the central and peripheral systems and that; MEM seems to be an interesting choice to alleviate multiple biomarkers, peripheral and central, at once.

\section{CLINICAL TRIALS WITH MEMANTINE}

It is clear that although preclinical MEM treatments for $\mathrm{AD}$ are hopeful, the clinical results are ineffective, none of them cure, and at most, they are able to slow the process of cognitive loss [106]. For example, in a clinical study (Clinical Trials identifier: NCT00322153), $28 \mathrm{mg}$ of MEM were administrated daily orally for 24 weeks [107]. The authors used the Severe Impairment Battery, a neuropsychological test for severely demented patients, for the assessment of cognitive function. The authors concluded that high doses of MEM provided behavioral benefits in patients with moderate to severe AD treated in combination with an acetylcholinesterase inhibitor (AChEIs). Howard and colleagues in a clinical study obtained similar results using donepezil (reversible AChEIs) in combination with MEM [108]. Thus, the combined therapy of AChEIs with MEM has the potential to provide benefits that either drug alone cannot produce. Galantamine is also a possible choice for these combined treatments since it inhibits acetylcholinesterase activity in the synapses and can modulate the nicotinic receptor. In a clinical study, the combinatory regimen galantamine plus MEM was evaluated in patients with mild to moderate probable AD. It was a clinical multicenter, double blind, randomized, parallel-group trial of 12 months of duration (Clinical trial: NCT01921972) [109]. The objective was to evaluate the efficacy of a combination of galantamine $24 \mathrm{mg} /$ day plus MEM $10 \mathrm{mg}$ b.i.d. (twice a day) with a dose titration of sixteen weeks. However, results of this study still have not been reported. If the expected results are positive, the drug association should have increased synaptic activity and prevented excitotoxicity. Another reported approach has been the combination masitinib (tyrosine kinase inhibitor; 3-6 mg/kg/day) with MEM or/and cholinesterase inhibitors (donepezil, rivastigmine, or galantamine) (Clinicaltrials.gov NCT00976118) that significantly improved the cognitive response [28]. As a result, the first conclusion we can obtain from these results is that more studies are necessary in order to evaluate potential combinatory treatments in order to delay or prevent $\mathrm{AD}$, which, after all, is a multifactorial disease and might need to be treated through multiple targets.

Annweiler and colleagues reported that the association of MEM plus vitamin D supplements had a statistically and clinically significant effect on the gain of global cognition improvement over AD symptoms [110, 111]. Likewise, the authors demonstrated that the combination was more effective than taking either substance alone. Interestingly, it has been reported that vitamin D shows neuroprotective effects such as antioxidant action, inhibiting the synthesis of inducible nitric oxide synthase, regulating the activity of $\gamma$-glutamyl transpeptidase, increasing the synthesis of nerve growth factor, showing anti-inflammatory properties and also attenuating $A \beta_{1-42}$ accumulation [111]. Therefore, the authors suggest that this association could act by a synergic effect increasing the neuroprotective action of MEM and, overall, providing a more complete protection in patients exposed to glutamatergic excitotoxicity. In addition, a new recent clinical trial (NCT01409694) named Alzheimer's disease Input of Vitamin D with mEmantine Assay (AD-IDEA) is being analyzed; however, no data have been reported from this study about the efficacy of the association improving cognitive function. Recently the same group reported in a clinical trial that MEM cognitive improvement depended on the plasmatic levels of vitamin D [112].

Interestingly MEM has been evaluated in the treatment of frontotemporal dementia (FTD) [113-115]. Lindquist and colleagues reported a familial case of a patient with FTD, an adult neurodegenerative disorder with dementia and behavioral disturbances treated with MEM with a maintenance dosage of $10 \mathrm{mg}$ twice a day. The authors suggest that, in this specific case of a patient with pathogenic mutation (R406W) in the microtubule associated protein tau (MAPT) gene, MEM treatment could stabilize the 
progression of symptoms of disease [113]. However, a multicenter, randomized, double-blind, placebo controlled clinical trial (NCT00545974) evaluated the efficacy of MEM in mild-to-moderate FTD and the main conclusion of this study was that MEM treatment do not ameliorate these dementia symptoms (Table 1) [114].

Since Parkinson's disease (PD) dementia and dementia with Lewy bodies have some pathological and biochemical similarities to AD, MEM have been proposed that could provide an improvement in these brain disorders (Table 1). Thus, the clinical trial NCT00855686 evaluated the efficacy and safety of MEM (20 mg per day over 6 months) in patients with mild to moderate PD dementia or dementia with Lewy bodies (DLB). In this study, patients were stratified according to diagnosis and randomly assigned to MEM or placebo in a double blind, parallel-group study. The main conclusion of this study was that the incidence of adverse events of patients treated with MEM was low and similar to the placebo group. The authors suggest that MEM could be a suitable strategy for mild to moderate DLB [115].

As a note of interest, and as it can be seen in Table 1, MEM has been evaluated as a potential therapy for other diseases such as PD. This is because MEM is an organic molecule of an aminoadamantane class similar to amantadine, which produces moderate symptomatic benefits in PD, related to tremor, tardive dyskinesia, chorea, and dementia [116]. However, the potential benefits of this drug are not mediated through the potentiation of dopamine effects, so further studies are necessary. Serafini and colleagues evidenced that the glutamatergic system could be involved in the pathology and treatment of depression via the modulation of post-synaptic ionotropic receptors including the NMDAR [86]. Thus, MEM has been reported that in association with sertraline, a selective inhibitor of serotonin reuptake, it shows a suitable efficacy profile in patients with major depression [88, 117-119]. Likewise, previous preclinical reported data demonstrated that the association of MEM with antidepressant drugs, such as fluoxetine and venlafaxine enhances the antidepressant effect of classical therapies. MEM associated with galantamine was investigated in the treatment of cognitive deficits in with schizophrenia [120, 121]. Others clinical trial evaluated, a part of MEM, additional non-pharmacological strategies for example the Environmental Ecological Therapy in AD [122, 123].

In addition, MEM has been evaluated for cognitive impairment associated with multiple sclerosis patients, and the objective is that MEM could improve the ability to work in severe cases of this devastating disease [124]. The results reported in Huntington's disease from a randomized, placebo-controlled study, which examines both efficacy and safety of MEM during long-term administration (52 weeks) in nondemented multiple sclerosis patients, were negative for cognitive impairment improvement. Ondo and colleagues reported that the administration of $20 \mathrm{mg}$ of MEM daily significantly improved motor symptoms, but failed to improve patient's cognition [125].

Cankurtaran and colleagues reported a case study of a 32-year-old woman with Huntington's disease where the drug association of risperidone with MEM was effective in the alleviation of cognitive deficits in this patient [126].

\section{CONCLUSION}

Although MEM shows an adequate profile in preclinical AD models, clinical data have not reported satisfactory results for curing the disease [127, 128]. Both cholinergic and glutamatergic dysfunctions are currently key neurochemical targets for the symptomatology of $\mathrm{AD}$ but drugs that alter these two pathways seem to have no real applications in the clinical cure of this disease, including MEM. Thus, the design of combined treatments seems to be the method to improve the current situation $[129,130]$. For example, therapy with AChEI and an MEM is an appropriate treatment strategy as the disease progresses, since there is a lack of other treatment options in moderate to severe $\mathrm{AD}[129,131]$.

The neuroprotective mechanisms of MEM in AD against neuronal loss (apoptosis decrease and mitochondrial alteration) and reduction of $\mathrm{A} \beta$ production could be attributed, at least in part, to its selective action blocking extrasynaptic NMDAR. Furthermore, in addition to extrasynaptic NMDAR blockade, recent preclinical data provides promising results about the brain decrease of $A \beta$ accumulation by MEM in transgenic animals and age normal animals. The new mechanism proposed by MEM would be the reduction in $A \beta$ production through the regulation of endocytosis of $A \beta P P$, which affects $A \beta$ production in neurons. The prevention of $A \beta$ excessive generation is important, because the vast majority of the preclinical studies evaluated reported that MEM attenuates or reduces soluble $\mathrm{A} \beta \mathrm{O}$ levels and fibrils and plaque generation, which is related with the process of memory improvement. 
Table 1

Examples of clinical research data reported with memantine

\begin{tabular}{cl}
\hline $\begin{array}{l}\text { ClinicalTrials.gov } \\
\text { identifier }\end{array}$ & Title of the assay \\
\hline NCT02234752 & $\begin{array}{l}\text { Galantamine and Memantine for Cognitive } \\
\text { Impairments in Schizophrenia }\end{array}$ \\
NCT01461174 & $\begin{array}{l}\text { Effects of Donepezil and Memantine on Cognitive } \\
\text { Functions After a Sleep Deprivation Challenge } \\
\text { in Healthy Volunteers }\end{array}$
\end{tabular}

NCT00334906 Study of Memantine in Assessment of Selected Measures of Volumetric MRI and Cognition in Moderate AD

NCT00551161 Magnetic Resonance Spectroscopy Study of Memantine in $\mathrm{AD}$

Objective of study

Publication

To examine the efficacy of the combination of galantamine and MEM for the treatment of cognitive deficits in outpatients with schizophrenia.

Assess the utility of sleep deprivation as a potential model for prediction of clinical efficacy using a combination of cognitive physiological endpoints.

Characterize the progression of disease using volumetric MRI techniques and cognitive outcome measures in patients with moderate AD treated with open-label MEM.

Characterize the progression of disease using MRS, CSF biomarkers, and cognitive outcome measures, and to determine whether changes in cognitive function on neuropsychological testing are correlated to changes in MR spectroscopic and/or CSF biomarkers.

NCT01261741 Investigation of Memantine in the Treatment of Memory, Concentration or Attention Problems

NCT00294554 Memantine for Treatment of Cognitive Impairment in Patients with Parkinson's Disease and Dementia

NCT01074619 Study on Cognitive Disorders of Multiple Sclerosis

NCT01876823 Memantine Plus Es-citalopram in Elderly Depressed Patients with Cognitive Impairment

NCT01409694 Alzheimer's Disease - Input of Vitamin D with Memantine Assay (AD-IDEA)

NCT01458470

A Trial of Memantine as Symptomatic Treatment for Early Huntington Disease (MITIGATE-HD)

NCT02462291 New Approach for Treatment of Behavioral Disorders in Alzheimer's Disease (Alzheimer's Behavioral and Cognitive Disorders)

NCT00857649 Efficacy and Safety of Memantine in Moderate to Severe Alzheimer's Disease

NCT00545974 Memantine (10 mg BID) for the Frontal and Temporal Subtypes of Frontotemporal Dementia

NCT00200538

Efficacy and Tolerability of Memantine in Frontotemporal Dementia (FTD) Patients

Memantine Versus Placebo in Parkinson's Disease Dementia or Dementia with Lewy Bodies

A new MEM indication in the treatment of subjective memory, concentration, or attention problems (subjective cognitive impairment) in the absence of dementia.

Evaluate the usefulness of MEM, compared to placebo (sugar pill), for the treatment of cognitive impairment in patients with idiopathic Parkinson's disease and dementia.

To determine if MEM is effective in the treatment on cognitive disorders of Relapsing - Remitting multiple sclerosis

Evaluate patients with Depression-MCI with MEM in addition to antidepressant treatment would benefit cognitive performance and lead to a low rate of conversion to dementia.

To compare the effect after 24 weeks of the oral intake of vitamin D3 (cholecalciferol) with the effect of a placebo on the change of cognitive performance in patients suffering from moderate $\mathrm{AD}$ or related disorders and receiving MEM

To determine the effect of MEM on movement, thinking and emotional difficulties in HD patients.

The aim of this trial will be to analyze the effects of Environmental Ecological Therapy, in people with severe AD.

The primary objective of this study is to examine the efficacy of MEM on cognition and behavioral symptoms in outpatients with moderate to severe dementia of the Alzheimer's type.

The primary objective of the study is to determine whether MEM is effective in slowing the rate of behavioral decline in frontotemporal dementia

The purpose of this trial is to assess the efficacy and tolerability of MEM in frontotemporal dementia patients after a one-year treatment.

The purpose of this study is to determine if MEM can provide benefits on clinical symptoms in patients with PD dementia or DLB. 
Table 1

(Continued)

\begin{tabular}{|c|c|c|c|}
\hline $\begin{array}{l}\text { ClinicalTrials.gov } \\
\text { identifier }\end{array}$ & Title of the assay & Objective of study & Publication \\
\hline NCT00630500 & $\begin{array}{l}\text { Efficacy and Safety of Memantine for Parkinson's } \\
\text { Disease Dementia (PDD) and Dementia with } \\
\text { Lewy Bodies (DLB) }\end{array}$ & $\begin{array}{l}\text { A 24-week placebo-controlled parallel group } \\
\text { multicenter trial to study the safety and efficacy } \\
\text { of MEM in patients with dementia associated } \\
\text { with PD and DLB. }\end{array}$ & \\
\hline NCT00768261 & $\begin{array}{l}\text { Corticolimbic Degeneration and Treatment of } \\
\text { Dementia }\end{array}$ & $\begin{array}{l}\text { The overall purpose of this research is to } \\
\text { determine if there is a relationship between } \\
\text { symptoms of Dementia of the Alzheimer's type } \\
\text { and changes in the size and shape of certain } \\
\text { brain structures during combined Donepezil } \\
\left(\text { Aricept }^{\circledR} \text { ) and MEM (Namenda }{ }^{\circledR} \text { ) treatment. }\right.\end{array}$ & \\
\hline
\end{tabular}

MEM, memantine; MRI, magnetic resonance imaging; AD, Alzheimer's disease; MRS, magnetic resonance spectroscopy; CSF, cerebrospinal fluid; PD, Parkinson's disease; MCI, mild cognitive impairment; HD, Huntington's disease; FTD, frontotemporal dementia; DLB, dementia with Lewy bodies.

Likewise, MEM inhibition of tau phosphorylation could be a process mediated also by the blockade of extrasynaptic NMDAR and the prevention of intracellular calcium increase. The activation of extrasynaptic NMDAR by glutamate and/or $A \beta$ leads to an increase in intracellular $\mathrm{Ca}^{2+}$ into the postsynaptic cells. Intracellular $\mathrm{Ca}^{2+}$ activates calpain and CDK5 pathway involved in tau phosphorylation. Furthermore, this process can lead to excessive neuronal oxidative stress formation that can destroy synaptic connections between neurons (memory loss) and induce activation of kinases involved in tau phosphorylation. It has also been reported that MEM have beneficial effects in preclinical AD models by decreasing the activation of microglia in the rodent brain and by increasing the production of trophic factors.

In addition, recent reports suggest a link between type 2 diabetes and $\mathrm{AD}$, currently denominated as type 3 diabetes where the alteration of hippocampal insulin receptor favors cognitive loss. Interestingly, pancreatic NMDAR are involved in insulin release, which leads to its use in the alleviation of these situations of insulin resistance. Furthermore, we hypothesized that the beneficial metabolic effects of MEM are mediated probably by an inhibition of peripheral (pancreatic) NMDAR and the blockade of hypothalamic $A \beta_{1-42}$ levels. Therefore, in the end it seems that $\mathrm{AD}$ is a cognitive disorder associated to metabolic alterations both in central and peripheral areas. Considering this hypothesis, we suggest that a combined treatment with MEM and another drug with antidiabetic effects could be a potential strategy to delay $\mathrm{AD}$ progression.

However, the lack of clinical efficacy of MEM in $\mathrm{AD}$ may be due to the administration of the drug too late when the disruption of neurons and/or synapses is advanced and impossible to reverse. Other possible explanations might be: 1) MEM needs to be administered with other drugs (antioxidants, antiinflammatory, GSK3 inhibitors, and others) in order to potentiate its effect on the delaying and prevention of the disease; and 2) MEM is effective in the treatment of neurons but it is hard to determine whether they remain active.

\section{ACKNOWLEDGMENTS}

This work was supported by the Spanish Ministry of Science and Innovation PI2016/01, CB06/05/0024 (CIBERNED), the European Regional Development Founds and MAT 2014-59134-R project. NIA 1R15AG050292 from GC. Research team from UB and URV belongs to 2014SGR-525 from Generalitat de Catalunya. ESL and MLG belong to 2014SGR-1023 and ESL, acknowledges the PhD scholarship FPI-MICINN (BES-2012-026083). CBZ is supported by grants from CONACyT Mexico (No. 0177594) and RDCT from Postdoctoral fellowship CONACYT No. 298337 and the Doctoral Program in Sciences in Molecular Biology in Medicine, LGAC Molecular Bases of Chronic Diseases-Degenerative and its Applications (000091, PNPC, CONACyT).

Authors' disclosures available online (https:// www.j-alz.com/manuscript-disclosures/17-0672r1).

\section{REFERENCES}

[1] Alzheimer's Association (2016) 2016 Alzheimer's disease facts and figures. Alzheimers Dement 12, 459-509.

[2] Alzheimer A, Stelzmann RA, Schnitzlein HN, Murtagh FR (1995) An English translation of Alzheimer's 1907 
paper, "Uber eine eigenartige Erkrankung der Hirnrinde". Clin Anat 8, 429-431.

[3] Vishal S, Sourabh A, Harkirat S (2011) Alois Alzheimer (1864-1915) and the Alzheimer syndrome. J Med Biogr 19, 32-33.

[4] Wilson RS, Segawa E, Boyle PA, Anagnos SE, Hizel LP, Bennett DA (2012) The natural history of cognitive decline in Alzheimer's disease. Psychol Aging 27, 1008-1017.

[5] De Felice FG (2013) Alzheimer's disease and insulin resistance: Translating basic science into clinical applications. J Clin Invest 123, 531-539.

[6] Balakrishnan K, Verdile G, Mehta PD, Beilby J, Nolan D, Galvão DA, Newton R, Gandy SE, Martins RN (2005) Plasma Abeta42 correlates positively with increased body fat in healthy individual. J Alzheimers Dis 8, 269-282.

[7] De Felice FG, Lourenco MV (2015) Brain metabolic stress and neuroinflammation at the basis of cognitive impairment in Alzheimer's disease. Front Aging Neurosci 7, 94.

[8] De la Monte SM, Wands JR (2008) Alzheimer's disease is type 3 diabetes-evidence reviewed. J Diabetes Sci Technol 2, 1101-1113.

[9] Jahn H (2013) Memory loss in Alzheimer's disease. Dialogues Clin Neurosci 15, 445-454.

[10] Querfurth HW, LaFerla FM (2010) Alzheimer's disease. $N$ Engl J Med 362, 329-344.

[11] Chneider LS, Mangialasche F, Andreasen N, Feldman H, Giacobini E, Jones R, Mantua V, Mecocci P, Pani L, Winblad B, Kivipelto M (2014) Clinical trials and late-stage drug development for Alzheimer's disease: An appraisal from 1984 to 2014. J Intern Med 275, 251-283.

[12] Castellano JM, Kim J, Stewart FR, Jiang H, DeMattos RB, Patterson BW, Fagan AM, Morris JC, Mawuenyega KG, Cruchaga C, Goate AM, Bales KR, Paul SM, Bateman RJ, Holtzman DM (2011) Human apoE isoforms differentially regulate brain amyloid- $\beta$ peptide clearance. Sci Transl Med 3, 89ra57.

[13] De Felice FG, Ferreira ST (2014) Inflammation, defective insulin signaling, and mitochondrial dysfunction as common molecular denominators connecting type 2 diabetes to Alzheimer disease. Diabetes $\mathbf{6 3}, 2262-2272$.

[14] Lipton SA (2006) Paradigm shift in neuroprotection by NMDA receptor blockade: Memantine and beyond. Nat Rev Drug Discov 5, 160-170.

[15] Lipton SA (2007) Pathologically-activated therapeutics for neuroprotection: Mechanism of NMDA receptor block by memantine and S-nitrosylation. Curr Drug Targets $\mathbf{8}$, 621-632.

[16] McAllister J, Ghosh S, Berry D, Park M, Sadeghi S, Wang KX, Parker WD, Swerdlow RH (2008) Effects of memantine on mitochondrial function. Biochem Pharmacol 75, 956-964.

[17] Allgaier M, Allgaier C (2014) An update on drug treatment options of Alzheimer's disease. Front Biosci (Landmark Ed.) 19, 1345-1354.

[18] Aracava Y, Pereira EF, Maelicke A, Albuquerque EX (2005) Memantine blocks alpha7 nicotinic acetylcholine receptors more potently than n-methyl-Daspartate receptors in rat hippocampal neurons. J Pharmacol Exp Ther 312, 1195-1205.

[19] Buisson B, Bertrand D (1998) Open-channel blockers at the human alpha4beta2 neuronal nicotinic acetylcholine receptor. Mol Pharmacol 53, 555-563.

[20] Akhtar MW, Sanz-Blasco S, Dolatabadi N, Parker J, Chon K, Lee MS, Soussou W, McKercher SR, Ambasudhan R, Nakamura T, Lipton SA (2016) Elevated glucose and oligomeric $\beta$-amyloid disrupt synapses via a common pathway of aberrant protein S-nitrosylation. Nat Commun 7.

[21] Masters CL, Bateman R, Blennow K, Rowe CC, Sperling RA, Cummings JL (2015) Alzheimer's disease. Nat Rev Dis Primers 15, 15056.

[22] Lipton SA (2005) The molecular basis of memantine action in Alzheimer's disease and other neurologic disorders: Low-affinity, uncompetitive antagonism. Curr Alzheimer Res 2, 155-165.

[23] Lipton SA (2007) Pathologically activated therapeutics for neuroprotection. Nat Rev Neurosci 8, 803-808.

[24] Tu S, Okamoto S, Lipton SA, Xu H (2014) Oligomeric A $\beta$-induced synaptic dysfunction in Alzheimer's disease. Mol Neurodegener 14, 48.

[25] Chen HS, Lipton SA (2006) The chemical biology of clinically tolerated NMDA receptor antagonists. J Neurochem 97, 1611-1626.

[26] Areosa SA, Sherriff F (2003) Memantine for dementia. Cochrane Database Syst Rev (3), CD003154.

[27] Cummings J, Lee G, Mortsdorf T, Ritter A, Zhong K (2017) Alzheimer's disease drug development pipeline: 2017. Alzheimers Dement (N Y) 3, 367-384.

[28] Piette F, Belmin J, Vincent H, Schmidt N, Pariel S, Verny M, Marquis C, Mely J, Hugonot-Diener L, Kinet JP, Dubreuil P, Moussy A, Hermine O (2011) Masitinib as an adjunct therapy for mild-to-moderate Alzheimer's disease: A randomised, placebo-controlled phase 2 trial. Alzheimers Res Ther 3, 16.

[29] Rush T, Buisson A (2014) Reciprocal disruption of neuronal signaling and $A \beta$ production mediated by extrasynaptic NMDA receptors: A downward spiral. Cell Tissue Res 356, 279-286.

[30] Bordji K, Becerril-Ortega J, Buisson A (2011) Synapses, NMDA receptor activity and neuronal $A \beta$ production in Alzheimer's disease. Rev Neurosci 22, 285-294.

[31] Lèveillè F, El Gaamouch F, Gouix E, Lecocq M, Lobner D, Nicole O, Buisson A (2008) Neuronal viability is controlled by a functional relation between synaptic and extrasynaptic NMDA receptors. FASEB $J \mathbf{2 2}$, 4258-4271.

[32] Paoletti P, Bellone C, Zhou Q (2013) NMDA receptor subunit diversity: Impact on receptor properties, synaptic plasticity and disease. Nat Rev Neurosci 14, 383-400.

[33] Hardy JA, Allsop D (1991) Amyloid deposition as the central event in the aetiology of Alzheimer's disease. Trends Pharmacol Sci 12, 383-388.

[34] Hardy JA., Higgins GA (1992) Alzheimer's disease: The amyloid cascade hypothesis. Science 256, 184-185.

[35] Hardy JA, Selkoe DJ (2002) The amyloid hypothesis of Alzheimer's disease: Progress and problems on the road to therapeutics. Science 297, 353-356.

[36] Walsh DM, Selkoe DJ (2007) A beta oligomers — a decade of discovery. J Neurochem 101, 1172-1184.

[37] Soejitno A, Tjan A, Purwata TE (2015) Alzheimer's disease: Lessons learned from amyloidocentric clinical trials. CNS Drugs 29, 487-502.

[38] Winblad B, Amouyel P, Andrieu S, Ballard C, Brayne C, Brodaty H, Cedazo-Minguez A, Dubois B, Edvardsson D, Feldman H, Fratiglioni L, Frisoni GB, Gauthier S, Georges J, Graff C, Iqbal K, Jessen F, Johansson G, Jönsson L, Kivipelto M, Knapp M, Mangialasche F, Melis R, Nordberg A, Rikkert MO, Qiu C, Sakmar TP, Scheltens P, Schneider LS, Sperling R, Tjernberg LO, Waldemar G, Wimo A, Zetterberg H (2016) Defeating Alzheimer's 
disease and other dementias: A priority for European science and society. Lancet Neurol 15, 455-532.

[39] Selkoe DJ, Hardy J (2016) The amyloid hypothesis of Alzheimer's disease at 25 years. EMBO Mol Med 8, 595-608.

[40] Viola KL, Klein WL (2015) Amyloid $\beta$ oligomers in Alzheimer's disease pathogenesis, treatment, and diagnosis. Acta Neuropathol 129, 183-206.

[41] Zhang W, Hao J, Liu R, Zhang Z, Lei G, Su C, Miao J, Li Z (2011) Soluble A $\beta$ levels correlate with cognitive deficits in the 12-month-old APPswe/PS1dE9 mouse model of Alzheimer's disease. Behav Brain Res 222, 342-350.

[42] Jadhav S, Cubinkova V, Zimova I, Brezovakova V, Madari A, Cigankova V, Zilka N (2015) Tau-mediated synaptic damage in Alzheimer's disease. Transl Neurosci 6, 214226.

[43] Guerrero-Muñoz MJ, Gerson J, Castillo-Carranza DL (2015) Tau oligomers: The toxic player at synapses in Alzheimer's disease. Front Cell Neurosci 9, 464.

[44] Danysz W, Parsons CG (2012) Alzheimer's disease, $\beta$-amyloid, glutamate, NMDA receptors andmemantine-searching for the connections. Br J Pharmacol 167, 324-352.

[45] Scholtzova H, Wadghiri YZ, Douadi M, Sigurdsson EM, Li YS, Quartermain D, Banerjee P, Wisniewski T (2008) Memantine leads to behavioral improvement and amyloid reduction in Alzheimer's-disease-model transgenic mice shown as by micromagnetic resonance imaging. J Neurosci Res 86, 2784-2791.

[46] Liu MY, Wang S, Yao WF, Zhang ZJ, Zhong X, Sha L, He M, Zheng ZH, Wei MJ (2014) Memantine improves spatial learning and memory impairments by regulating NGF signaling in APP/PS1 transgenic mice. Neuroscience 273, 141-151.

[47] Parsons CG, Gilling KE, Jatzke C (2008) Memantine does not show intracellular block of the NMDA receptor channel. Eur J Pharmacol 587, 99-103.

[48] Ito K, Tatebe T, Suzuki K, Hirayama T, Hayakawa M, Kubo H, Tomita T, Makino M (2017) Memantine reduces the production of amyloid- $\beta$ peptides through modulation of amyloid precursor protein trafficking. Eur J Pharmacol 798, 16-25.

[49] Meisner F, Scheller C, Kneitz S, Sopper S, Neuen-Jacob E, Riederer P, ter Meulen V, Koutsilieri E, German Competence Network HIV/AIDS (2008) Memantine upregulates BDNF and prevents dopamine deficits in SIV-infected macaques: A novel pharmacological action of memantine. Neuropsychopharmacology 33, 2228-2236.

[50] Nyakas C, Granic I, Halmy LG, Banerjee P, Luiten PG (2011) The basal forebrain cholinergic system in aging and dementia. Rescuing cholinergic neurons from neurotoxic amyloid- $\beta 42$ with memantine. Behav Brain Res 221, 594-603.

[51] Devi L, Ohno M (2016) Cognitive benefits of memantine in Alzheimer's 5XFAD model mice decline during advanced disease stages. Pharmacol Biochem Behav 144, 60-66.

[52] Figueiredo CP, Clarke JR, Ledo JH, Ribeiro FC, Costa CV, Melo HM, Mota-Sales AP, Saraiva LM, Klein WL, Sebollela A, De Felice FG, Ferreira ST (2013) Memantine rescues transient cognitive impairment caused by highmolecular-weight $\mathrm{A} \beta$ oligomers but not the persistent impairment induced by low-molecular-weight oligomers. J Neurosci 33, 9626-9634.
[53] Mazanetz MP, Fischer PM (2007) Untangling tau hyperphosphorylation in drug design for neurodegenerative diseases. Nat Rev Drug Discov 6, 464-479.

[54] Iqbal K, Grundke-Iqbal I (2008) Alzheimer neurofibrillary degeneration: Significance, etiopathogenesis, therapeutics and prevention. J Cell Mol Med 12, 38-55.

[55] Ittner LM, Ke YD, Delerue F, Bi M, Gladbach A, van Eersel J, Wölfing H, Chieng BC, Christie MJ, Napier IA, Eckert A, Staufenbiel M, Hardeman E, Götz J (2010) Dendritic function of tau mediates amyloid- $\beta$ toxicity in Alzheimer's disease mouse models. Cell 142, 387-397.

[56] Fein JA, Sokolow S, Miller CA, Vinters HV, Yang F, Cole GM, Gylys KH (2008) Co-localization of amyloid $\beta$ and tau pathology in Alzheimer's disease synaptosomes. Am J Pathol 172, 1683-1692.

[57] Takahashi RH, Capetillo-Zarate E, Lin MT, Milner TA, Gouras GK (2010) Co-occurrence of Alzheimer's disease $\beta$-amyloid and tau pathologies at synapses. Neurobiol Aging 31, 1145-1152.

[58] Lee MS, Tsai LH (2003) Cdk5: One of the links between senile plaques and neurofibrillary tangles? J Alzheimers Dis 5, 127-137.

[59] Kamat PK, Kalani A, Rai S, Swarnkar S, Tota S, Nath C, Tyagi N (2016) Mechanism of oxidative stress and synapse dysfunction in the pathogenesis of Alzheimer's disease: Understanding the therapeutics strategies. Mol Neurobiol 53, 648-661.

[60] Shah K, Lahiri DK (2017) A tale of the good and bad: Remodeling of the microtubule network in the brain by Cdk5. Mol Neurobiol 54, 2255-2268.

[61] Zimmer ER, Kalinine E, Haas CB, Torrez VR, Souza DO, Muller AP, Portela LV (2012) Pretreatment with memantine prevents Alzheimer-like alterations induced by intrahippocampal okadaic acid administration in rats. Curr Alzheimer Res 9, 1182-1190.

[62] Clark I, Atwood C, Bowen R, Paz-Filho G, Vissel B (2012) Tumor necrosis factor-induced cerebral insulin resistance in Alzheimer's disease links numerous treatment rationales. Pharmacol Rev 64, 1004-1026.

[63] Maqbool M, Mobashir M, Hoda N (2016) Pivotal role of glycogen synthase kinase-3: A therapeutic target for Alzheimer's disease. Eur J Med Chem 107, 63-81.

[64] Beurel E, Grieco SF, Jope RS (2015) Glycogen synthase kinase-3 (GSK3): Regulation, actions, and diseases. Pharmacol Ther 148, 114-131.

[65] Llorens-Martìn M, Jurado J, Hernández F, Avila J (2014) GSK-3 $\beta$, a pivotal kinase in Alzheimer disease. Front Mol Neurosci 7, 46.

[66] De Sarno P, Bijur GN, Zmijewska AA, Li X, Jope RS (2006) In vivo regulation of GSK3 phosphorylation by cholinergic and NMDA receptors. Neurobiol Aging 27, 413-422.

[67] Martinez-Coria H, Green KN, Billings LM, Kitazawa M, Albrecht M, Rammes G, Parsons CG, Gupta S, Banerjee P, LaFerla FM (2010) Memantine improves cognition and reduces Alzheimer's-like neuropathology in transgenic mice. Am J Pathol 176, 870-880.

[68] Schmidt C, Wolff M, von Ahsen N, Zerr I (2012) Alzheimer's disease: Genetic polymorphisms and rate of decline. Dement Geriatr Cogn Disord 33, 84-89.

[69] Han HJ, Kim BC, Lee JY, Ryu SH, Na HR, Yoon SJ, Park HY, Shin JH, Cho SJ, Yi HA, Choi MS, Heo JH, Park KW, Kim KK, Choi SH (2012) Response to rivastigmine transdermal patch or memantine plus rivastigmine patch 
is affected by apolipoprotein E genotype in Alzheimer patients. Dement Geriatr Cogn Disord 34, 167-173.

[70] Han HJ, Kwon JC, Kim JE, Kim SG, Park JM, Park KW, Park KC, Park KH, Moon SY, Seo SW, Choi SH, Cho SJ (2015) Effect of rivastigmine or memantine add-on therapy is affected by butyrylcholinesterase genotype in patients with probable Alzheimer's disease. Eur Neurol 73, 23-28.

[71] Wroolie TE, Kenna HA, Williams KE, Powers BN, Holcomb M, Lazzeroni L, Rasgon NL (2009) Cognitive effects of memantine in postmenopausal women at risk of dementia: A pilot study. Acta Neurol Scand 119, 172-179.

[72] McGeer PL, Rogers J, McGeer EG (2016) Inflammation, antiinflammatory agents, and Alzheimer's disease: The last 22 years. J Alzheimers Dis 54, 853-857.

[73] McGeer PL, Schulzer M, Edith GM (1996) Arthritis and anti-inflammatory agents as possible protective factors for Alzheimer's disease. Neurology 47, 425-432.

[74] Calsolaro V, Edison P (2016) Neuroinflammation in Alzheimer's disease: Current evidence and future directions. Alzheimers Dement 12, 719-732.

[75] Zhao X, Marszalec W, Toth PT, Huang J, Yeh JZ, Narahashi T (2006) In vitro galantamine-memantine co-application: Mechanism of beneficial action. Neuropharmacology 51, 1181-1191.

[76] Tsai KL, Hsueh-Fen Chang HF, Wu SN (2013) The inhibition of inwardly rectifying $\mathrm{K}+$ channels by memantine in macrophages and microglial cells. Cell Physiol Biochem 31, 938-951.

[77] Kaindl AM, Degos V, Peineau S, Gouadon E, Chhor V, Loron G, Le Charpentier T, Josserand J, Ali C, Vivien D, Collingridge GL, Lombet A, Issa L, Rene F, Loeffler JP, Kavelaars A, Verney C, Mantz J, Gressens P (2012) Activation of microglial N-methyl-Daspartate receptors triggers inflammation and neuronal cell death in the developing and mature brain. Ann Neurol 72, 536-549.

[78] De Felice FG, Velasco PT, Lambert MP, Viola K, Fernandez SJ, Ferreira ST, Klein WL (2007) Abeta oligomers induce neuronal oxidative stress through an N-methyl-Daspartate receptor-dependent mechanism that is blocked by the Alzheimer drug memantine. J Biol Chem 282, 11590-11601.

[79] Wu HM1, Tzeng NS, Qian L, Wei SJ, Hu X, Chen SH, Rawls SM, Flood P, Hong JS, Lu RB (2009) Novel neuroprotective mechanisms of memantine: Increase in neurotrophic factor release from astroglia and anti-inflammation by preventing microglial activation. Neuropsychopharmacology 34, 2344-2357.

[80] Caumont AS, Octave JN, Hermans E (2006) Amantadine and memantine induce the expression of the glial cell linederived neurotrophic factor in C6 glioma cells. Neurosci Lett 394, 196-201.

[81] Willard LB, Hauss-Wegrzyniak B, Danysz W, Wenk GL (2000) The cytotoxicity of chronic neuroinflammation upon basal forebrain cholinergic neurons of rats can be attenuated by glutamatergic antagonism or cyclooxygenase-2 inhibition. Exp Brain Res 134, 58-65.

[82] Rosi S, Ramirez-Amaya V, Vazdarjanova A, Esparza EE, Larkin PB, Fike JR, Wenk GL, Barnes CA (2009) Accuracy of hippocampal network activity is disrupted by neuroinflammation: Rescue by memantine. Brain 32, 2464-2477.

[83] Rosi S, Vazdarjanova A, Ramirez-Amaya V, Worley PF, Barnes CA, Wenk GL (2006) Memantine protects against
LPS-induced neuroinflammation, restores behaviorallyinduced gene expression and spatial learning in the rat. Neuroscience 142, 1303-1315.

[84] Anand R, Gill KD, Mahdi AA (2014) Therapeutics of Alzheimer's disease: Past, present and future. Neuropharmacology 76, 27-50.

[85] Rèus GZ, Stringari RB, Kirsch TR, Fries GR, Kapczinski F, Roesler R, Quevedo J (2010) Neurochemical and behavioural effects of acute and chronic memantine administration in rats: Further support for NMDA as a new pharmacological target for the treatment of depression? Brain Res Bull 81, 585-589.

[86] Serafini G, Pompili M, Innamorati M, Dwivedi Y, Brahmachari G, Girardi P (2013) Pharmacological properties of glutamatergic drugs targeting NMDA receptors and their application in major depression. Curr Pharm Des 19, 1898-1922.

[87] Garcia LS, Comim CM, Valvassori SS, Rèus GZ, Barbosa LM, Andreazza AC, Stertz L, Fries GR, Gavioli EC, Kapczinski F, Quevedo J (2008) Acute administration of ketamine induces antidepressant-like effects in the forced swimming test and increases BDNF levels in the rat hippocampus. Prog Neuropsychopharmacol Biol Psychiatry 32, 140-144.

[88] Amidfar M, Réus GZ, Quevedo J, Kim YK, Arbabi M (2017) Effect of co-administration of memantine and sertraline on the antidepressant-like activity and brainderived neurotrophic factor (BDNF) levels in the rat brain. Brain Res Bull 128, 29-33.

[89] Rogóz Z1, Skuza G, Legutko B (2008) Repeated co-treatment with fluoxetine and amantadine induces brain-derived neurotrophic factor gene expression in rats. Pharmacol Rep 60, 817-826.

[90] Jeanblanc J, He DY, Carnicella S, Kharazia V, Janak PH, Ron D (2009) Endogenous BDNF in the dorsolateral striatum gates alcohol drinking. J Neurosci 29, 1349413502.

[91] Zhu G, Li J, He L, Wang X, Hong X (2015) MPTPinduced changes in hippocampal synaptic plasticity and memory are prevented by memantine through the BDNFTrkB pathway. Br J Pharmacol 172, 2354-2368.

[92] Zhao H, Alam A, San CY, Eguchi S, Chen Q, Lian Q, Ma D (2017) Molecular mechanisms of brain-derived neurotrophic factor in neuro-protection: Recent developments. Brain Res 1665, 1-21.

[93] Marquard J, Otter S, Welters A, Stirban A, Fischer A, Eglinger J, Herebian D, Kletke O, Klemen MS, Stožer A, Wnendt S, Piemonti L, Köhler M, Ferrer J, Thorens B, Schliess F, Rupnik MS, Heise T, Berggren PO, Klöcker N, Meissner T, Mayatepek E, Eberhard D, Kragl M, Lammert E (2015) Characterization of pancreatic NMDA receptors as possible drug targets for diabetes treatment. Nat Med 21, 363-372.

[94] Marquard J, Stirban A, Schliess F, Sievers F, Welters A, Otter S, Fischer A, Wnendt S, Meissner T, Heise T, Lammert E (2016) Effects of dextromethorphan as add-on to sitagliptin on blood glucose and serum insulin concentrations in individuals with type 2 diabetes mellitus: A randomized, placebo-controlled, double-blinded, multiple crossover, single-dose clinical trial. Diabetes Obes Metab 18, 100-103.

[95] Kullmann S, Heni M, Hallschmid M, Fritsche A, Preissl $\mathrm{H}$, Häring HU (2016) Brain insulin resistance at the crossroads of metabolic and cognitive disorders in humans. Physiol Rev 96, 1169-1209. 
[96] Bedse G, Di Domenico F, Serviddio G, Cassano T (2015) Aberrant insulin signaling in Alzheimer's disease: Current knowledge. Front Neurosci 9, 204.

[97] Clarke JR, Lyra E, Silva NM, Figueiredo CP, Frozza RL, Ledo JH, Beckman D, Katashima CK, Razolli D, Carvalho BM, Frazão R, Silveira MA, Ribeiro FC, Bomfim TR, Neves FS, Klein WL, Medeiros R, LaFerla FM, Carvalheira JB, Saad MJ, Munoz DP, Velloso LA, Ferreira ST, De Felice FG (2015) Alzheimer-associated A $\beta$ oligomers impact the central nervous system to induce peripheral metabolic deregulation. EMBO Mol Med 7, 190-210.

[98] Welters A, Lammert E, Mayatepek E, Meissner T (2017) Need for better diabetes treatment: The therapeutic potential of NMDA receptor antagonists. Klin Padiatr 229, 14-20.

[99] Wollheim CB, Maechler P (2015) Beta cell glutamate receptor antagonists: Novel oral antidiabetic drugs? Nat Med 21, 310-311.

[100] Arrieta-Cruz I, Knight CM, Gutiérrez-Juárez R (2015) Acute exposure of the mediobasal hypothalamus to amyloid- $\beta 25-35$ perturbs hepatic glucose metabolism. J Alzheimers Dis 46, 843-848.

[101] Arrieta-Cruz I, Gutiérrez-Juárez R (2016) The role of insulin resistance and glucose metabolism dysregulation in the development of Alzheimer's disease. Rev Invest Clin 68, 53-58.

[102] Troncone L, Luciani M, Coggins M, Wilker EH, Ho CY, Codispoti KE, Frosch MP, Kayed R, Del Monte F (2016) $A \beta$ amyloid pathology affects the hearts of patients with Alzheimer's disease: Mind the heart. $J$ Am Coll Cardiol 68, 2395-2407.

[103] Morris JK, Honea RA, Vidoni ED, Swerdlow RH, Burns JM (2014) Is Alzheimer's disease a systemic disease? Biochim Biophys Acta 1842, 1340-1349.

[104] Zhang Y, Zhou B, Deng B, Zhang F, Wu J, Wang Y, Le Y, Zhai Q (2013) Amyloid- $\beta$ induces hepatic insulin resistance in vivo via JAK2. Diabetes 62, 1159-1166.

[105] Zhang Y, Zhou B, Zhang F, Wu J, Hu Y, Liu Y, Zhai Q (2012) Amyloid- $\beta$ induces hepatic insulin resistance by activating JAK2/STAT3/SOCS-1 signaling pathway. Diabetes 61, 1434-1443.

[106] Alley GM, Bailey JA, Chen D, Ray B, Puli LK, Tanila H, Banerjee PK, Lahiri DK (2010) Memantine lowers amyloid-beta peptide levels in neuronal cultures and in APP/PS1 transgenic mice. J Neurosci Res 88, 143-154.

[107] Grossberg GT, Manes F, Allegri RF, Gutiérrez-Robledo LM, Gloger S, Xie L, Jia XD, Pejović V, Miller ML, Perhach JL, Graham SM (2013) The safety, tolerability, and efficacy of once-daily memantine $(28 \mathrm{mg})$ : A multinational, randomized, double-blind, placebo-controlled trial in patients with moderate-to-severe Alzheimer's disease taking cholinesterase inhibitors. CNS Drugs 27, 469-478.

[108] Howard R, McShane R, Lindesay J, Ritchie C, Baldwin A, Barber R, Burns A, Dening T, Findlay D, Holmes C, Jones R, Jones R, McKeith I, Macharouthu A, O'Brien J, Sheehan B, Juszczak E, Katona C, Hills R, Knapp M, Ballard C, Brown RG, Banerjee S, Adams J, Johnson T, Bentham P, Phillips PP (2015) Nursing home placement in the Donepezil and Memantine in Moderate to Severe Alzheimer's Disease (DOMINO-AD) trial: Secondary and post-hoc analyses. Lancet Neurol 14, 1171-1181.

[109] Peters O, Fuentes M, Joachim KL, Jessen F, Luckhaus C, Kornhuber, Pantel JJ, Hüll M, Schmidtke K, Rüther E, Möller HJ, Kurz A, Wiltfang J, Maier W, Wiese B, Frölich L, Heuser I (2015) Combined treatment with memantine and galantamine-CR compared with galantamine-CR only in antidementia drug naïve patients with mild-to-moderate Alzheimer's disease. Alzheimers Dement (NY) 1, 198-204.

[110] Annweiler C, Herrmann FR, Fantino B, Brugg B, Beauchet O (2012) Effectiveness of the combination of memantine plus vitamin D on cognition in patients with Alzheimer disease: A pre-post pilot study. Cogn Behav Neurol 25, 121-127.

[111] Annweiler C, Karras SN, Anagnostis P, Beauchet O (2014) Vitamin D supplements: A novel therapeutic approach for Alzheimer patients. Front Pharmacol 5, 6.

[112] Lemire P, Brangier A, Beaudenon M, Duval GT, Annweiler C (2017) Cognitive changes under memantine according to vitamin D status in Alzheimer patients: An exposed/unexposed cohort pilot study. J Steroid Biochem Mol Biol, doi: 10.1016/j.jsbmb.2016.12.019

[113] Lindquist SG, Holm IE, Schwartz M, Law I, Stokholm J, Batbayli M, Waldemar G, Nielsen JE (2008) Alzheimer disease-like clinical phenotype in a family with FTDP-17 caused by a MAPT R406W mutation. Eur J Neurol 15, 377-385.

[114] Vercelletto M, Boutoleau-Bretonniere C, Volteau C, Puel M, Auriacombe S, Sarazin M, Michel BF, Couratier P, Thomas-Antérion C, Verpillat P, Gabelle A, Golfier V, Cerato E, Lacomblez L, French research network on Frontotemporal dementia (2011) Memantine in behavioral variant frontotemporal dementia: Negative results. J Alzheimer Dis 23, 749-759.

[115] Boxer AL, Knopman DS, Kaufer DI, Grossman M, Onyike C, Graf-Radford N, Mendez M, Kerwin D, Lerner A, Wu CK, Koestler M, Shapira J, Sullivan K, Klepac K, Lipowski K, Ullah J, Fields S, Kramer JH, Merrilees J, Neuhaus J, Mesulam MM, Miller BL (2013) Memantine in patients with frontotemporal lobar degeneration: A multicentre, randomised, double-blind, placebo-controlled trial. Lancet Neurol 12, 149-156.

[116] Aarsland D, Ballard C, Walker Z, Bostrom F, Alves G, Kossakowski K, Leroi I, Pozo-Rodriguez F, Minthon L, Londos E (2009) Memantine in patients with Parkinson's disease dementia or dementia with Lewy bodies: A doubleblind, placebo-controlled, multicenter trial. Lancet Neurol 8, 613-618.

[117] Amidfar M, Khiabany M, Kohi A, Salardini E, Arbabi M, Roohi Azizi M, Zarrindast MR, Mohammadinejad P, Zeinoddini A, Akhondzadeh S (2017) Effect of memantine combination therapy on symptoms in patients with moderate-to-severe depressive disorder: Randomized, double-blind, placebo-controlled study. J Clin Pharm Ther 42, 44-50.

[118] Almeida RC, Souza DG, Soletti RC, López MG, Rodrigues AL, Gabilan NH (2006) Involvement of PKA, MAPK/ERK and CaMKII, but not PKC in the acute antidepressant-like effect of memantine in mice. Neurosci Lett 395, 93-97.

[119] Pelton GH, Harper OL, Roose SP, Marder K, D'Antonio K, Devanand DP (2016) Combined treatment with memantine/es-citalopram for older depressed patients with cognitive impairment: A pilot study. Int $J$ Geriatr Psychiatry 31, 648-655.

[120] Veronese N, Solmi M, Luchini C, Lu RB, Stubbs B, Zaninotto L, Correll CU (2016) Acetylcholinesterase inhibitors and memantine in bipolar disorder: A systematic review and best evidence synthesis of the efficacy and safety for multiple disease dimensions. $J$ Affect Disord 197, 268-280. 
[121] Koola MM, Buchanan RW, Pillai A, Aitchison KJ, Weinberger DR, Aaronson ST, Dickerson FB (2014) Potential role of the combination of galantamine and memantine to improve cognition in schizophrenia. Schizophr Res 157, 84-89.

[122] Herrmann N, Gauthier S, Boneva N, Lemming OM 10158 Investigators (2013) A randomized, double-blind, placebo-controlled trial of memantine in a behaviorally enriched sample of patients with moderate-to-severe Alzheimer's disease. Int Psychogeriatr 25, 919-927.

[123] Gonzalez MT, Kirkevold M (2014) Benefits of sensory garden and horticultural activities in dementia care: A modified scoping review. J Clin Nurs 23, 2698-2715.

[124] Peyro Saint Paul L, Creveuil C, Heinzlef O, De Seze J, Vermersch P, Castelnovo G, Cabre P, Debouverie M, Brochet B, Dupuy B, Lebiez P, Sartori É, Clavelou P, Brassat D, Lebrun-Frenay C, Daplaud D, Pelletier J, Coman I, Hautecoeur P, Tourbah A, Defer G (2016) Efficacy and safety profile of memantine in patients with cognitive impairment in multiple sclerosis: A randomized, placebo-controlled study. J Neurol Sci 363, 69-76.

[125] Ondo WG, Mejia NI, Hunter CB (2007) A pilot study of the clinical efficacy and safety of memantine for Huntington's disease. Parkinsonism Relat Disord 13, 453-454.
[126] Cankurtaran ES, Ozalp E, Soygur H, Cakir A (2006) Clinical experience with risperidone and memantine in the treatment of Huntington's disease. J Natl Med Assoc 98, 1353-1355.

[127] Minkeviciene R, Banerjee P, Tanila H (2004) Memantine improves spatial learning in a transgenic mouse model of Alzheimer's disease. J Pharmacol Exp Ther 311, 677-682.

[128] Reisberg B, Doody R, Stoffler A, Schmitt F, Ferris S, Mobius HJ (2003) Memantine in moderate to severe Alzheimer's disease. N Engl J Med 348, 1333-1341.

[129] Choi SH, Park KW, Na DL, Han HJ, Kim EJ, Shim YS, Lee JH (2011) Tolerability and efficacy of memantine addon therapy to rivastigmine transdermal patches in mild to moderate Alzheimer's disease: A multicenter, randomized, open-label, parallel-group study. Curr Med Res Opin 27, 1375-1383.

[130] Tariot PN, Farlow MR, Grossberg GT, Graham SM, McDonald S, Gergel I (2004) Memantine treatment in patients with moderate to severe Alzheimer disease already receiving donepezil. JAMA 21, 317-324.

[131] Ehret MJ, Chamberlin KW (2015) Current practices in the treatment of Alzheimer disease: Where is the evidence after the phase III trials? Clin Ther 37, 1604-1616. 